\title{
Thoracoscopic excision versus radiofrequency ablation of the sympathetic chain as a treatment for palmar hyperhidrosis: comparative study
}

\author{
Mohamed Saber Mostafa ${ }^{1 *}$ (D, Mohammed Elsherbeny ${ }^{1}$, Ahmed Abdelbarr $^{2}$ and Sameh Abdelhay ${ }^{1}$
}

\begin{abstract}
Background: Hyperhidrosis is an excess sweat secretion. Various modalities of treatment exist for hyperhidrosis. Although medical treatment is the first line of treatment, its long-term outcome is not satisfactory. In this study, we compared the results of thoracoscopic excision with that of radiofrequency ablation of the sympathetic chain as a treatment of palmar hyperhidrosis.

Results: During the period from January 2014 to December 2017, 42 patients with palmar hyperhidrosis after failure of medical treatment presented to Departments of Pediatric Surgery and Neurosurgery, Faculty of Medicine. They were 26 males and 16 females. Their ages ranged between 11 and 42 years (mean 21.78 years). Twenty patients underwent thoracoscopic excision of the sympathetic chain (in Pediatric Surgery Department), while 22 patients underwent radiofrequency ablation of the sympathetic chain (in Neurosurgery Department). For the thoracoscopic sympathectomy group, the mean operative time was 27.39 min, the mean length of hospital stay was $24.78 \mathrm{~h}$, the mean sweating scale decreased from 3.28 preoperatively to 1.331 year postoperatively, and the main postoperative complication was compensatory hyperhidrosis (40\%). For the radiofrequency ablation group, the mean operative time was $55 \mathrm{~min}$, the mean length of hospital stay was $20.64 \mathrm{~h}$, the mean sweating scale decreased from 3.29 preoperatively to 1.571 year postoperatively, and the main postoperative complication was recurrence of hyperhidrosis (27\%).
\end{abstract}

Conclusion: Thoracoscopic excision is more effective than radiofrequency ablation of the sympathetic chain in improving palmar hyperhidrosis. However, it has a higher risk of developing compensatory hyperhidrosis.

Keywords: Thoracoscopic sympathectomy, Radiofrequency ablation, Sympathetic chain, Hyperhidrosis

\section{Background}

Hyperhidrosis is an excessive sweating that can occur in different body areas with plentiful eccrine glands, such as palms, soles, face, and axillae [1]. Hyperhidrosis may affect patient's psychological life, interferes with their daily living activities, and increases the risk of skin infection $[2,3]$.

\footnotetext{
* Correspondence: mohamed.saber.mostafa@gmail.com

'Department of Pediatric Surgery, Faculty of Medicine, Ain Shams University, Cairo, Egypt

Full list of author information is available at the end of the article
}

Treatment of hyperhidrosis can be non-surgical which includes topical therapy and botulinum toxin injection, but their effect has limitations $[4,5]$.

The other option after failed medical treatment is the surgical option which is left as a final way of management for severe and refractory cases. Surgery can carry some limitations as well as medical treatment. These limitations are the need for general anesthesia, postoperative pain, compensatory reaction in other sites, and the scar from the surgery $[6,7]$.

\section{Springer Open}

(ㅇ The Author(s). 2020 Open Access This article is licensed under a Creative Commons Attribution 4.0 International License, which permits use, sharing, adaptation, distribution and reproduction in any medium or format, as long as you give appropriate credit to the original author(s) and the source, provide a link to the Creative Commons licence, and indicate if changes were made. The images or other third party material in this article are included in the article's Creative Commons licence, unless indicated otherwise in a credit line to the material. If material is not included in the article's Creative Commons licence and your intended use is not permitted by statutory regulation or exceeds the permitted use, you will need to obtain permission directly from the copyright holder. To view a copy of this licence, visit http://creativecommons.org/licenses/by/4.0/. 
Radiofrequency (RF) therapy uses electromagnetic energy, which is deposited in or near the nerve tissue. This technique was first used for pain therapy and few studies in the literature have used this technique for treating palmar hyperhidrosis. The technique has the advantage of low cost, being non-invasive and easy to apply $[8,9]$.

Our aim in this study was to compare the results of thoracoscopic sympathectomy with that of radio frequency ablation of the sympathetic chain as a treatment for patients with palmar hyperhidrosis after failed medical treatment.

\section{Methods}

During the period from January 2014 to December 2017, patients presented to Pediatric Surgery Department and Neurosurgery Department, Faculty of Medicine, with palmar hyperhidrosis, after failure of medical treatment for at least 3 months, were included in the study. Medical treatment was either by using topical aluminum chloride, oral anticholinergics, or multiple sessions of Botox injection.

The patients underwent either thoracoscopic excision or radiofrequency ablation of the sympathetic chain. This prospective cohort study was done after approval from university hospital's ethical committee.

Patients chose one of the two techniques after explaining the advantages and disadvantages of each procedure mentioned in the literature. Despite there was no randomization in choosing the technique, we tried to minimize the selection bias as much as possible by choosing homogenous patients to participate in this study to easily compare results. We also standardized the advantages and the disadvantages of both techniques which were explained to patients either by pediatric or neurosurgeons trying to eliminate bias on selecting the technique.
Thoracoscopic excision of the sympathetic chain was done under general anesthesia, and the patient in supine position with slight elevation of the affected side, a 30degree thoracoscope was introduced through the 5th intercostal space in the midaxillary line. Two trocars were introduced through the 3rd intercostal space in the anterior and posterior axillary lines. T3 and T4 ganglia were hemoclipped and excised (Fig. 1).

Radiofrequency ablation of the sympathetic chain was done either under general anesthesia or sedation in cooperative patients. With the patient in a prone position, two 18 gauge radiofrequency needle electrodes were introduced to target $\mathrm{T} 3$ and T4 ganglia (Fig. 2) under fluoroscopic guidance which helped in protecting the lung and the pleura (Fig. 3).

The two techniques were compared as regard, the operative time, the length of hospital stay, the improvement of hyperhidrosis (the sweating scale), and the procedure-related complications like compensatory hyperhidrosis and recurrence of hyperhidrosis.

We used the hyperhidrosis disease severity score (HDSS) to assess the outcome of both operations, which involves asking the patient to describe his sweating status pre- and postoperative. A score of 1 or 2 was classified as mild or moderate hyperhidrosis and a score of 3 or 4 was classified as severe hyperhidrosis. A one-point decrease in the patient's sweating scale means $50 \%$ decrease in sweat production and 2-point decrease means $80 \%$ decrease in sweat production [10].

The patients were evaluated immediately after the operation, before discharge from hospital, after 1 week of discharge, and every 3 months for at least 1 year.

\section{Results}

During the specified time period, 42 patients with palmar hyperhidrosis after failure of medical treatment presented to Pediatric Surgery Department and

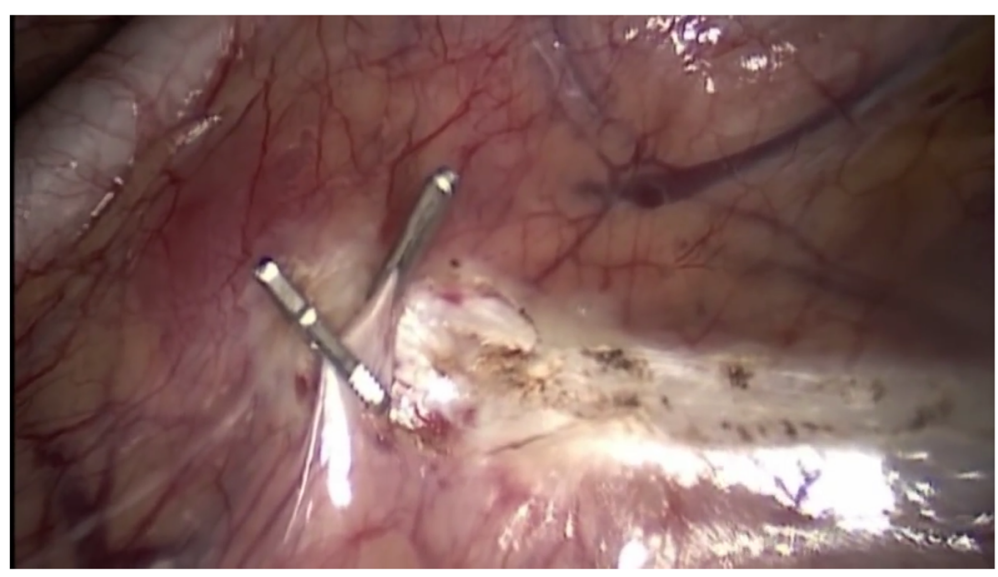

Fig. 1 Hemoclipping of T3 sympathetic ganglia during thoracoscopy 


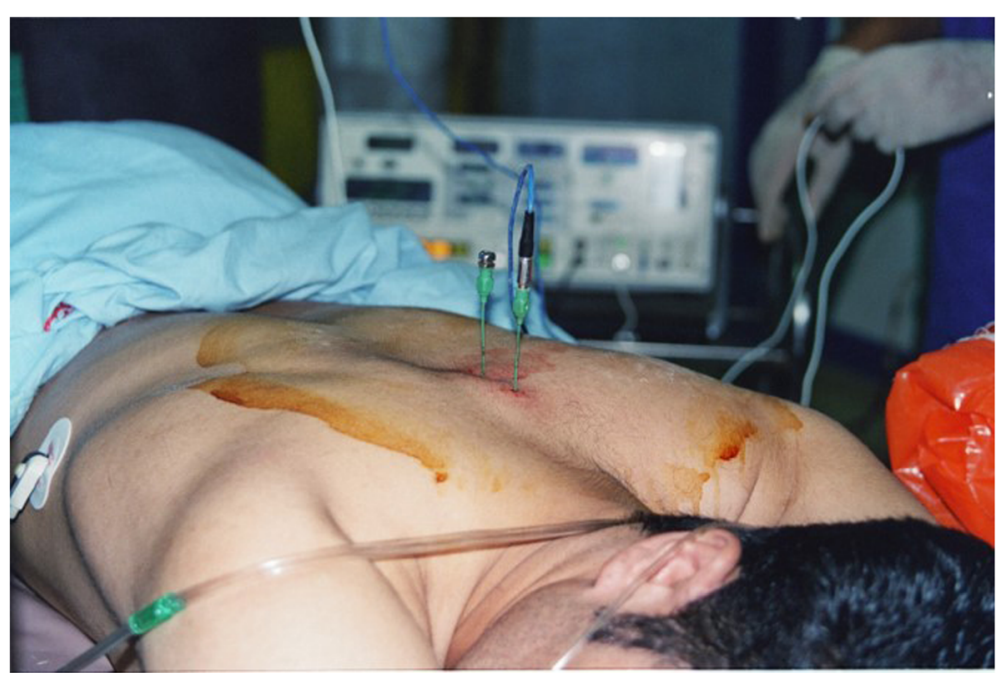

Fig. 2 Positioning of the patient for radiofrequency ablation of the sympathetic chain

Neurosurgery Department, Faculty of Medicine. They were 26 males and 16 females. Their ages ranged between 11 and 42 years (mean 21.78 years, median 20 years).

Twenty patients underwent thoracoscopic excision of the sympathetic chain (in Pediatric Surgery Department), while 22 patients underwent radiofrequency ablation of the sympathetic chain (in Neurosurgery Department). All the patients had bilateral palmar hyperhidrosis, but each side was operated upon in a separate session with an interval of at least 3 months between the two sides. The rationale of this decision was to give the patients an opportunity to decide if they were satisfied with the operation and wanted to have the other side operated upon or they were bothered by the compensatory hyperhidrosis complicating the intervention.

For the thoracoscopic sympathectomy group, they were 12 males and 8 females, the age of the patients ranged between 11 and 30 years, the operative time ranged between 20 and 40 min (mean operative time was $27.39 \mathrm{~min}$ ), the length of hospital stay ranged between 14 and $72 \mathrm{~h}$ (mean length of hospital stay was $24.78 \mathrm{~h}$ ), the mean sweating scale decreased from 3.28 preoperatively to 1.06 immediately postoperatively and persisted at 1.06 in the early follow-up to 1.331 year postoperatively ( $p$ value $<0.001$ ), and the postoperative

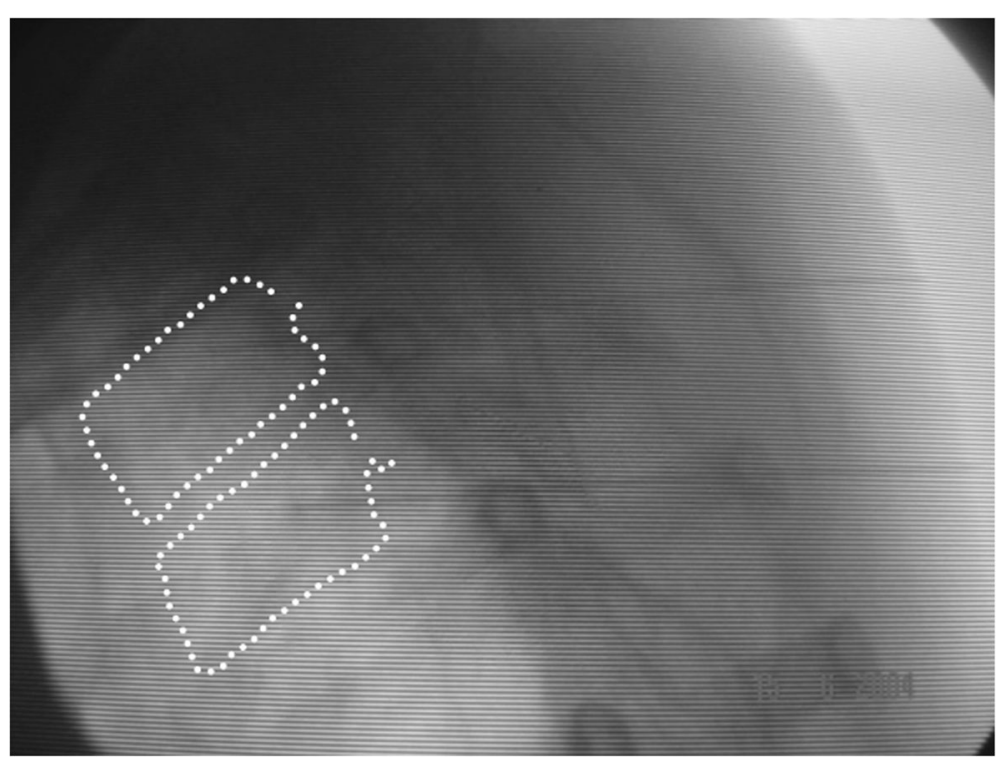

Fig. 3 Needle ablation of T3 and T4 ganglia under fluoroscopic guidance 
complications were compensatory hyperhidrosis (in the form of increased sweating of the back) in 8 patients (40\%), recurrence of the condition in two patients (10\%), and superficial cautery burn in two patients (10\%).

For the radiofrequency ablation group, they were 14 males and 8 females, the age of the patients ranged between 11 and 42 years, the operative time ranged between 45 and $75 \mathrm{~min}$ (mean operative time was $55 \mathrm{~min}$ ), the length of hospital stay ranged between 12 and $72 \mathrm{~h}$ (mean length of hospital stay was $20.64 \mathrm{~h}$ ), the mean sweating scale decreased from 3.29 preoperatively to 1.07 immediately postoperatively to 1.43 in the early follow-up to 1.571 year postoperatively ( $p$ value < 0.001 ), and the postoperative complications were recurrence of the condition in 6 patients (27\%), thoracic neuritis in 4 patients (18\%), compensatory hyperhidrosis in two patients (9\%), and pneumothorax in two patients (9\%).

All patients with successful outcome were asked to describe their sweating status after having procedure, and they all documented that their sweating became unnoticeable and not interfering with their daily activities anymore.

\section{Discussion}

Thoracic sympathetic chain has nerves which control sweat production in the palms; hence, cutting these nerves can improve palmar hyperhidrosis [11]. The success rate of thoracic sympathectomy can approach $90 \%$ in most of the literature. The invasive nature of this surgery, the need for general anesthesia, and the postoperative pain which accompany this procedure have saved this procedure as a last resort for treating hyperhidrosis $[6-8,12]$.

The other alternative is using radiofrequency waves to ablate the sympathetic chain and avoid the surgical drawbacks [13]. Little data has been written in the literature about the comparison between both techniques and if one is superior to the other.

In our study, 20 patients had thoracoscopic thoracic sympathectomy as their management and 22 patients chose radiofrequency ablation for treating their condition. A multidisciplinary team (MDT) meeting consisting of a pediatric surgeon and a neurosurgeon was held to discuss treating options with the patients and let them choose between the two techniques after discussing the advantages and disadvantages of each procedure.

The operative time for thoracoscopic sympathectomy ranged between 20 and $40 \mathrm{~min}$ compared with longer time of radiofrequency procedure which ranged between 45 and $75 \mathrm{~min}$. The slightly shorter procedure time was attributed to the familiarity of this technique to the pediatric surgeons and better learning curve in comparison to the less common use of radiofrequency as a treatment for hyperhidrosis by neurosurgeons.

The postoperative hospital stay was almost the same in both techniques and ranged between 12 to $72 \mathrm{~h}$ which is a quite strong proof of the simplicity and safety of both techniques. Despite that there was no need for a chest tube insertion in both techniques, a short hospital stay was needed to control pain and monitor any postoperative chest complications.

The success rate of thoracoscopic thoracic sympathectomy in our series reached $90 \%$ with only two recurrent cases. Our result was comparable to other results listed in the literature which ranged between 90 and $97 \%$. Purtuloglu et al. have reported $95 \%$ success rate in 46 patients [2]. In their big series on 407 patients with palmar hyperhidrosis, Vannucci et al. reported 1\% (4 cases) recurrence among their patients [14]. In our series, the recurrence was unilateral in both cases and both patients chose not to have any further intervention and we recommended trying medical management for a longer period of time.

The success rate of the radiofrequency ablation in our study was $72 \%$ which is also comparable to the literature results. Purtuloglu et al. had a success rate of $75 \%$ in a percutaneous technique and $95 \%$ in a thoracoscopic approach [2]. Romero et al. reported a higher success rate of $92 \%$ in their study and attributed this significant higher success rate to their choice of target for ablation (T3 and T4 ganglions) and strict application of radiofrequency's physical principle that consisted in the positioning of the cannula tip parallel to the ganglion [15].

The most common complication in both techniques was compensatory hyperhidrosis $(\mathrm{CH})$, in the form of increased sweating of the back [16]. $\mathrm{CH}$ was more common in the surgical technique compared to the radiofrequency ablation. The former had $40 \%$ incidence of $\mathrm{CH}(n=8)$ and the later showed $10 \%$ incidence of $\mathrm{CH}(n=2)$. Our incidence of $\mathrm{CH}$ was a bit different from the literature and this can be attributed to the low number of cases in our series. Compensatory hyperhidrosis was described, in all patients, as tolerable and rarely affecting their daily activities compared to their condition before the operation (score 2 in the HDSS).

The incidence of $\mathrm{CH}$ was $35 \%$ in both techniques as documented by Purtuloglu et al. [2]. Other studies documented different incidences of $\mathrm{CH}$, as high as $90 \%$ in a study done by Fredmann et al. [17] and $88 \%$ in a study done by Lin et al. [18]. It was $67 \%$ in a series done by Zacherl et al. [19], 86.4\% in a study done by Gossot et al. [20], and $59.8 \%$ in a study done by Rex et al. [21]. We did not report any cases who had Horner syndrome even after long-term follow-up.

There was an unusual complication after thoracoscopic sympathectomy which was the superficial cautery 
burn at the skin level which occurred in two patients (10\%). This complication happened due to equipment problem related to the insulation in the hook used for cauterizing the ganglia. This superficial burn was so minor and did not require any intervention except for topical cream for a week postoperatively, and this complication was avoided in other patients by replacing the faulty equipment.

In the other group, there were two cases who had pneumothorax due to needle puncture inside the chest which led to introducing small amount of air discovered by chest X-ray. The pneumothorax was not severe enough to warrant a chest tube insertion and resolved spontaneously.

\section{Conclusion}

Thoracoscopic excision is more effective than radiofrequency ablation of the sympathetic chain in treating palmar hyperhidrosis. However, it has a higher risk of developing compensatory hyperhidrosis.

\section{Acknowledgements}

Not applicable.

\section{Authors' contributions}

MM and ME shared in writing, collecting, and analyzing the data.

AA shared in performing the radiofrequency technique in the neuro surgery department and collected all data about those patients.

SA was the clinical supervisor and helped in editing this manuscript.

I confirm that all authors have read and approved the manuscript.

\section{Funding}

No funding was needed.

\section{Availability of data and materials}

The data and material are available for review.

\section{Ethics approval and consent to participate}

This study was approved by the IRB of Surgery Department, Faculty of Medicine, Ain Shams University with reference number 00006379.

A written consent was obtained from a parent or guardian for participants under 16 years old. A written consent was obtained directly from patients if they were over 16 years old.

\section{Consent for publication}

I give my consent and all authors' consent for publication in the Annals of Pediatric Surgery Journal

\section{Competing interests}

There was no conflict of interest in this project.

\section{Author details}

${ }^{1}$ Department of Pediatric Surgery, Faculty of Medicine, Ain Shams University, Cairo, Egypt. ${ }^{2}$ Department of Neurosurgery, Faculty of Medicine, Ain Shams University, Cairo, Egypt.

Received: 9 March 2020 Accepted: 18 June 2020

Published online: 16 July 2020

\section{References}

1. Walling HW, Swick BL. Treatment options for hyperhidrosis. Am J Clin Dermatol. 2011;12:285-95.

2. Purtuloglua T, Atima A, Deniza S, Kavaklib K, Sapmazb E, Gurkokb S, Kurta E, Turanc A. Effect of radiofrequency ablation and comparison with surgical sympathectomy in palmar hyperhidrosis. European Journal of CardioThoracic Surgery. 2013;43:e151-4.

3. Nawrocki S, Cha J. Botulinum toxin: pharmacology and injectable administration for the treatment of primary hyperhidrosis. J Am Acad Dermatol 2020; 82 (4): 969-979. PMID: 31811879 . DOI: https://doi.org/10. 1016/j.jaad.2019.11.042.

4. Hoorens I, Ongenae K. Primary focal hyperhidrosis: current treatment options and a step-by-step approach. J Eur Acad Dermatol Venereol. 2012; 26:1-8.

5. De Campos JR, Hashmonai M, Licht PB, Schick CH, Bischof G, Cameron AE, et al. Treatment options for primary hyperhidrosis. Am J Clin Dermatol. 2012;13:139.

6. Solish N, Bertucci V, Dansereau A, Hong HC, Lynde C, Lupin M, et al. A comprehensive approach to the recognition, diagnosis, and severity-based treatment of focal hyperhidrosis: recommendations of the Canadian hyperhidrosis advisory committee. Dermatol Surg. 2007;33:908-23.

7. Prasad A, Ali M, Kaul S. Endoscopic thoracic sympathectomy for primary palmar hyperhidrosis. Surg Endosc. 2010;24:1952-7.

8. Guo L, Kubat NJ, Nelson TR, Isenberg RA. Meta-analysis of clinical efficacy of pulsed radio frequency energy treatment. Ann Surg. 2012;255:457-67.

9. Kim JB, Park CK, Kum DY. The effect of thoracoscopic sympathicotomy at the fourth rib (r4) for the treatment of palmar and axillary hyperhidrosis. Korean J Thorac Cardiovasc Surg. 2011;44:154-8.

10. A comprehensive approach to the recognition, diagnosis, and severitybased treatment of focal hyperhidrosis: recommendations of the Canadian Hyperhidrosis Advisory Committee, Dermatologic Surgery, August 2007, pages 908-923.

11. Pei G, Liu Y, Liu Q, Min X, Yang Y, Wang S, Liu J, Wang J, Huang Y. The safety and feasibility of intraoperative near-infrared fluorescence imaging with indocyanine green in thoracoscopic sympathectomy for primary palmar hyperhidrosis. Thorac Cancer 2020; 11 (4): 943-949. PMID: 32061064. PMCID: PMC7113049. DOl: https://doi.org/10.1111/1759-7714.13345.

12. Wolosker N, Faustino CB, de Campos JRM, Kauffman P, Yazbek G, Fernandes PP, Cucato G. Comparative analysis of the results of videothoracoscopic sympathectomy in the treatment of hyperhidrosis in adolescent patients. J Pediatr Surg 2020; 55 (3): 418-424. PMID: 32063368. DOI: https://doi.org/10. 1016/j.jpedsurg.2019.11.004.

13. Hasimoto FN, Cataneo DC, Hasimoto EN, Ximenes AMG, Cataneo AJM. Radiofrequency in the treatment of primary hyperhidrosis: systematic review and meta-analysis. Clin Auton Res 2020; 30 (2):111-120. PMID: 31552511. DOl: https://doi.org/10.1007/s10286-019-00640-w.

14. Vannucci F, Araújob JA. Thoracic sympathectomy for hyperhidrosis: from surgical indications to clinical results. Thorac Dis. 2017;9(Suppl 3):S178-92.

15. Romero FR, Cataneo DC, Cataneo AJM. Effect of radiofrequency ablation and comparison with surgical sympathectomy in palmar hyperhidrosis. Semin ThoracicSurg. 2018;30:362-6.

16. Han JW, Kim JJ, Kim YH, Kim IS, Jeong SC. New sympathicotomy for prevention of severe compensatory hyperhidrosis in patients with primary hyperhidrosis. J Thorac Dis 2020; 12 (3): 765-772. PMID: 32274143. PMCID: PMC7138987. DOI: https://doi.org/10.21037/jtd.2019.12.91.

17. Fredmann B, Zohar E, Shachor D, Bendahan J, Jedeikin R. Video-assisted transthoracic sympathectomy in the treatment of primary hyperhidrosis: friend or foe? Surg Laparosc Endosc Percutan Tech. 2000;4:226-9.

18. Lin TS, Wang NP, Huang LC. Pitfalls and complication avoidance associated with transthoracic endoscopic sympathectomy for primary hyperhidrosis (analysis of 2200 cases). Int J Surg Investig. 2001;2:377-85.

19. Zacherl J, Huber ER, Imhof M, Plas EG, Herbst F, Fugger R. Long-term results of 630 thoracoscopic sympathicotomies for primary hypehidrosis: the Vienna experience. Eur J Surg Suppl. 1998;580:43-6.

20. Gossot D, Galetta D, Pascal A, et al. Long-term results of endoscopic thoracic sympathectomy for upper limb hyperhidrosis. Ann Thorac Surg. 2003;75:1075-9.

21. Rex LO, Drott C, Claes G, Go“ thberg G, Dalman P. The Borås experience of endoscopic thoracic sympathicotomy for palmar, axillary, facial hyperhidrosis and facial blushing. EurJ Surg Suppl 1998; 580: 23-26.

\section{Publisher's Note}

Springer Nature remains neutral with regard to jurisdictional claims in published maps and institutional affiliations. 